\title{
NOTAS SOBRE EL POEMA "MÍA" DE RUBEN DARIO
}

Alonso Benavides

El crítico y poeta español Pedro Salinas, en su excelente trabajo La poesía de Rubén Darío, propone como tema central de la poesía ruberiana el del amor erótico. Dice que el amor expresado por los patricios de la lírica amorosa, Dante, Petrarca, Garcilaso, Bécquer, etc. fue un amor total, pero que Darío siente una parcialidad manifiesta por todo lo que llega al amor por medio de los sentidos. Dice también que "los sentidos son los señores absolutos de la lírica de amor de Rubén durante su primera época." Aunque esta explicación de la poesía amorosa de Darío es de valor para iluminar, obra, poeta y hombre, es, sin embargo, muy confinante, al punto de que el autor parece a veces querer forzar toda la poesía amorosa de Darío dentro del marco que su tesis propone. Pasa superficialmente por algunos poemas, sin llegar a descubrir sutilezas importantes y sin notar que quizá muestren otras posibles concepciones del amor no inspiradas por el afán erótico solamente.

Así, dice por ejemplo que "Mía", poemita muy extraño del volumen Prosas profanas, "es la sublimación de la poesía erótica."2

Hay en "Mía" mucho más que simple erotismo sensual, como esperamos demonstrar en las líneas que siguen. "Mía" podría ser uno de los más significativos productos de la inspiración dariana, tanto por su concepción formal adelantada en muchos años a la poesía de su tiempo, como por la singular sinceridad con que el autor nos habla de sus más profundos sentimientos.

Veamos el poema:

Mia: Asi te llamas.

¿Qué más armonia?

Mía: luz del dia;

mia; rosas, llamas.

¡Qué aromas derramas

en el alma mia!

si sé que me amas

iOh Mia! iOh Mia!

Tu sexo fundiste

con mi sexo fuerte

fundiendo dos bronces. 


\section{Yo triste, tú triste... \\ ¿No has de ser entonces \\ mía hasta la muerte?}

Lo que primero llama la atención es la forma. Son versos de ritmo entrecortado, versos escuetos, simples. En ellos están ausentes el brillo verbal y la cadencia musical obvia, marcas características del Rubén de otras composiciones. Por ser tan modesto en este sentido, el poema deja una impresión de sinceridad, de comunicación sin elaboraciones.

El alma de Darío, que Vargas Vila describió como "hecha de abismos y serenidades, pero áfona, rebelde a revelarse por algo que no fuera el ritmo musical y el golpe sonoro,"3 ha emergido de sus profundidades y ha volcado en "Mía" anhelos de amor antes no expresados.

Es como si Darío en otros poemas de Azul y Prosas profanas, hubiera tratado de evadir la dimensión espiritual de la mujer, por lo menos en cuanto a su deseo de posesión se refiere. Parece que quisiera convencerse de que la mujer deseada es sólo cuerpo, y la posesión máxima pudiera ser lograda con sólo poseerlo sensualmente. En "Mía" podemos entrever una concepción diferente y más genuina, más real aunque dolorosa: que la mujer es alma y cuerpo y que el hombre desea la posesión de ambas partes. Mientras una es fácil presa, sin embargo, la otra es esquiva y huidiza:

\section{Tu sexo fundiste con mi sexo fuerte fundiendo dos bronces. \\ Yo triste, tú triste... $¿$ No has de ser entonces mía hasta la muerte?}

El poeta de "Mía" no es el de:

iAmar, reir! La vida es corta.

Gozar de abril es lo que importa

en el loco delirio.

Ni el que desde el otro extremo solloza:

iSeñor que la fe se muere!

Señor mira mi dolor.

¡miserere! ¡miserere!.. .

Dame la mano Señor. . .

Es, nos parece, el filósofo profundo que por un momento se ha detenido entre la rosa y el clavo para meditar, alma al desnudo, sobre la tragedia del amor erótico y sus límites.

En "Mía" Darío encara la verdad. En otros poemas se vale de su habilidad para sumergirse en un mundo sibarítico de ensueños donde puede satisfacer poéticamente 
su afán erótico. ¿Y encuanto al alma? . La plenitud de una consonancia espiritual entre él y su amada es un elusivo misterio que no está ya a su alcance. La desilusión resultante es el tema principal de "Mía".

Veamos el poema parte por parte:

En el primer verso la exaltación eufórica es intensa. Ya Salinas notó en forma aguda cómo Darío consigue expresar el sentimiento de posesión por medio de la sustantivación del adjetivo mia, con lo que logra un poder expresivo inusitado: "Lo que distingue a esta hembra y la coloca por encima de todo, no son personales, individuales cualidades 'suyas', no: es tan solo la circunstancia de haber sido esa 'mia', de haber sido poseída, esto es, de no ser suya de ella." 4

Esta fusión de mujer y posesión, es para el poeta la más bella armonía. Así suya, es toda luz, perfume, pasión. Caricia para los sentidos del apasionado amante:

¿Qué más armonia?

Mía: luz del dia;

mia: rosas, llamas.

Aún en tono eufórico, el poeta menciona el éxtasis que esta posesión le provoca:

\section{¿Qué aroma derramas en el alma mia!}

Acto seguido y, como no queriendo dudar y así disminuir la intensidad de la alegría, rompiendo la magia de aquel mundo de fantasía, se dice a sí mismo:

\section{si sé que me amas}

iOh Mia! iOh Mia!

Por qué el "si sé" que da la impresión de ser respuesta positiva a una incertidumbre repentina? Es como si Darío se dijera: ¿por qué dudar, si sé que eres mía, que me amas?

Es desesperado el tono del siguiente terceto que pregona la más poderosa razón que pueda presentarse en defensa de lo justo de su euforia viril:

\section{Tu sexo fundiste con mi sexo fuerte fundiendo dos bronces.}

¡Qué mejor prueba! Ha quedado convencido? No. Lo intuimos por el seguiente

\section{Yo triste, tú triste.}

Oración elíptica que expresa el intenso dolor y el desengaño que siente el poeta. La ausencia del necesario verbo causa que este verso exprese el decaimiento del ánimo sentido. Una persona transida de dolor se expresa así, seca, entrecortadamente. 
El tono ha cambiado. La exaltación de las primeras estrofas contrasta con lo monótono de este verso de seis sílabas con hemistiquio al medio que repite con desmayo “triste" dos veces, “tú triste." ¿No se siente también desengañada la mujer que sabe que todo termina fugazmente?

Con qué fuerza nos llega entonces lo dicho en las dos últimas líneas:

\title{
¿No has de ser estonces mia hasta la muerte?
}

Su impacto nos deja con el convencimiento, más por intuición que por lógica, de que Darío anhela la plenitud de una posesión que se le escapa. En lo físico se pertenecen, pero luego de la fusión de los "dos bronces" la posesión se desvanece. La pregunta del poeta parece equivaler a: ¿serás siempre mía?

Es dolorosa la realidad y Darío la ha dejado así, expresada pero sin comentario, para dejarla como espina, esta vez sin el mitigante de la consolación poética de por ejemplo:

\author{
- Calla, calla, princesa - dice el hada madrina-; \\ el caballo con alas hacia aqui se encamina, \\ en el cinto la espada y en la mano el azor, \\ el feliz caballero que te adora sin verte, \\ y que llega de lejos, vencedor de la Muerte, \\ a encenderte los labios con un beso de amor.
}

El poema "Mía" ha empezado en ritmo acelerado, ritmo que casi se apaga con las líneas finales. Deja la impresión de haber terminado prematuramente por lo sintético de su expresión y lo truncado de las frases que, embrionarias, parecen necesitar una mayor elaboración.

El Darío de Azul y el resto de Prosas profanas se caracteriza por una mayor continuidad, y un mayor desarrollo tanto en el tema como en el ritmo de los versos. Para expresarlo en términos musicales, antes era poeta de tono más instrumental y clásico, en "Mía" suena un solo acorde que formula brevemente, y pasa de nota a nota consiguiendo dejar solamente una insinuación, un bosquejo.

Si observamos ahora el poema entero, vemos que la estructura está organizada de manera que los dos primeros cuartetos representan la realidad poética, el ensueño inspirado por la posesión carnal de la mujer.

La tercera estrofa, alrededor de la cual gira todo el resto del poema, representa la realidad física que inspiró al poeta aquel mundo de ensueño:

Tu sexo fundiste

con mi sexo fuerte

fundiendo dos bronces.

Sobre este significado es que Darío ha meditado. 
Es importante notar, sin embargo, que no ha colocado estas líneas al comienzo, lo que hubiera sido natural, ya que fue lo primero cronológicamente. Cambia Darío el orden intencionalmente porque lo que busca es expresar primero la suposición lírica, presentar la realidad inspiradora después, y luego terminar el poema con la realidad espiritual, la amarga verdad que causa su desencanto y que exclame:

\section{$¿$ No has de ser entonces mia hasta la muerte?}

El desenlace desgarra sin piedad la ilusión primera para llegar a lo esencial de la realidad de la última estrofa. Darío ha tocado así, de modo dramático, un tema universal. Nos ha elevado para luego dejarnos caer de mayor altura y lograr más intensamente su propósito.

La aparente simplicidad de "Mía" y su hermetismo, han causado que se le califique de "copos de espuma lírica que se desvanecem apenas se les quiere recoger en las manos,"5 o que se diga que el objeto del ansia de Darío "no era la musa, ni a lo clásico ni a lo romántico: era la mujer de carne y hueso." Ambas son verdades, pero verdades parciales. Rodó intuyó lo leve y huidizo de su esencia. Salinas insistió sólo en el significado de los dos primeros cuartetos que, efectivamente, expresan un delirio de posesión erótica, pero que constituyen no el tema del poema sino un elemento.

Además de los autores ya mencionados, contadísimos críticos se han ocupado de "Mía"7, quizá porque no encaje en el conjunto de la obra lírica de Rubén Darío. Como ya anotamos, carece del colorido característico, de la elegancia verbal y el pictorialismo de otros poemas. Es también nuevo el énfasis que Darío pone en el pensamiento más bien que en la forma, tendencia pocas veces aparente en la poesía modernista de aquella época.

Mucho después, poetas como Juan Ramón Jiménez (1881-1958), Antonio Machado (1875-1939) y muchos otros, empiezan a depurar la forma y ahondar el sentimiento. Con "Mía" sonó la nota antes sorda que luego otros poetas hicieron suya, logrando en el proceso algunos de los más bellos versos de la poesía contemporánea.

¿No encontramos ya en la palabra mía un desusado valor comunicativo que no fluye de la palabra como símbolo de significados convencionales, sino de un sentido nuevo que ha adquirido en el poema? . Esta voluntad de indagar en las recónditas facetas expresivas de una palabra es una nueva posibilidad que llevan a su máxima expresión portas como Juan Ramón Jiménez, por ejemplo, que escribe en 1918:

\section{Los nubarrones tristes}

le dan sombras al mar.

El agua férrea,
parece un duro campo llano
de minas agotadas
en un arruinamiento
de ruinas.

iNada! La palabra, aqui, encuentra hoy, para mi, su sitio, 


\section{como un cadáver de palabra \\ que se tendiera en su sepulcro \\ natural.}

\section{¡Nada!}

La novedad en el uso del lenguaje la explica el crítico Antonio Sánchez Barbudo de la siguiente manera: "Todo se concentra en una visión-mar, en un sentimiento-angustia, y en una palabra: iNada!. Y cuando al fin, en el verso último, aparece la palabra sola, esta exclamación, en ella se resume el mar infinito, y la muerte, y su temblor."

Nos parece que el origen germinal de este gusto por arrancarle a la palabra su mensaje oculto está ya en el olvidado poemita de Rubén Darío que hemos analizado.

A pesar de su brevedad, el poema "Mía" no sólo nos revela a un nuevo Darío profundamente sencillo y cándido, sino que nos permite coger al vuelo el momento en que, como poeta en suafán descubridor, ensaya formas para expresar sus más hondos anhelos de hombre y artista.

Alonso Benavides

Beloit College

Wisconsin

\section{NOTAS}

${ }^{1}$ Salinas, Pedro, La poesía de Rubén Darío (Buenos Aires: Ed. Losada, 1957), p. 68.

2 Salinas, p. 69.

3 Torres Rioseco, Arturo, Rubén Darío, Casticismo y Americanismo, (Massachusetts: Harvard University Press, 1931), p. 52.

${ }^{4}$ Salinas, p. 68.

${ }^{5}$ Rodó, José Enrique, "Rubén Darío: su personalidad literaria,su última obra". Introducción a Prosas Profanas, (París: Librería de la viuda de Ch. Bouret, 1925), p. 27.

${ }^{6}$ Salinas, p. 69.

${ }^{7}$ Ver Feustle, Joseph, Antología comentada del Modernismo, ed. Porrata y Santana, (California: University of California Press, 1974), pp. 266-270.

${ }^{8}$ Sánchez Barbudo, Antonio, Cincuenta poemas comentados (Madrid: Gredos, "Campo Abierto," 1963), pp. 25-27. 